\title{
Mechanical Characteristics for Rocks under Different Paths and Unloading Rates under Confining Pressures
}

\author{
Bing Dai, Guoyan Zhao, Longjun Dong, and Chen Yang \\ School of Resources and Safety Engineering, Central South University, Changsha 410083, China \\ Correspondence should be addressed to Longjun Dong; rydong001@csu.edu.cn
}

Received 9 December 2014; Accepted 27 January 2015

Academic Editor: Alicia Gonzalez-Buelga

Copyright (C) 2015 Bing Dai et al. This is an open access article distributed under the Creative Commons Attribution License, which permits unrestricted use, distribution, and reproduction in any medium, provided the original work is properly cited.

\begin{abstract}
To investigate mechanical characteristics of rocks under different unloading conditions, triaxial tests are carried out with initial confining pressures of 10,20 , and $30 \mathrm{MPa}$ and unloading rates of $0.05 \sim 1 \mathrm{MPa} / \mathrm{s}$ in three stress paths. Results show that the increment of axial strain is far less than that of the lateral strain. The unloading rates of confining pressures have less influence on variation of strain and lateral increment in path I. The variation of axial increment strain in the same time is slightly larger than the variation of lateral increment; D-value is influenced by unloading rates of confining pressures in path II. The variation of axial strain increment decreases firstly and then increases with the variation of confining pressures. The relation decreases and then increases with unloading rates increases in path III. The dilatancy angle decreases with initial confining pressures increases. The vary rates of dilatancy angle from initial point of dilatancy angle to peak point of dilatancy angle increase with the unloading rates of confining pressures. In the same rates, the vary rates of dilatancy angle from the initial point of the dilatancy angle to peak point of the dilatancy angle in path I are greater than those in path II.
\end{abstract}

\section{Introduction}

Rock masses at depth are under a triaxial stress equilibrium state before an excavation. Excavating an opening disturbs the original in situ stress field, which will lead to stress redistribution around the excavation. With the increase of mining depth, the excavation becomes more and more serious and the stability of the surrounding rock get weaker and weaker $[1,2]$. It would lead to severe rock failure, such as rockburst, spalling, collapse, and other geological disasters [3-5]. These behaviors have been observed in hard rock mines and in deep civil tunnels around the world [6]. Many studies have shown that, during the excavation of deep-buried tunnels and caverns, the surrounding rock masses undergo unloading process [7-9].

However, investigations indicated that rock behavior under unloading is different from that under loading [10-12]. To achieve a clear understanding of the rock behavior under unloading, many experimental studies have been carried out. R. Q. Huang and D. Huang [13] obtained the determination of Poisson's ratio of rock material by changing the axial stress and unloading lateral stress test. Huang et al. [14] reveals that rock bursts during tunneling in a high in situ stress area could be controlled or reduced by lowering the excavation speed or applying precautionary measures to control the displacement of surrounding rocks. Li et al. [15] studied the fatigue damage behavior of sandstone after high temperature under triaxial unloading.

Many experts and scholars have made great effects on the research of factors such as anisotropy, size effect, shear, and rheological behavior, which have great influence on mechanical characteristics of unloading rock. Besides the above factors, unloading rates of rocks and unloading paths also have a significant impact on the mechanical characteristics of unloading rock. About stress path, Li et al. $[5,6]$ discussed the influence of stress path on excavation unloading response by PFC and obtained the characteristics of the unloading process of rocks under high initial stress. Cai [16] studied the influence of stress path on tunnel excavation responsenumerical tool selection and modeling strategy. Guo et al. $[17,18]$ studied mechanical properties of Jintan mine rock salt under complex stress paths and found that the strength of rock salt was only slightly affected by loading strain rate, which is different from other brittle rocks. And it also made 
some effects on unloading rate. Qiu et al. [19] carried out truetriaxial unloading tests on granite specimens and obtained the degree of violence during failure and the associated $\mathrm{AE}$ energy release in the strain burst process are dependent on the unloading rate. Gang et al. [1] reported the deformation and strength characters of jointed rock mass under unloading stress states. Qiu et al. [20] studied characteristics of strength of rocks under different unloading rates and indicated that the strength of the rock will increase as the unloading rate is higher.

These theoretical studies help us to understand the influence of the unloading rate and unloading path on the excavation stability. However, the influence of the unloading rate and unloading path on mechanical characteristics has not been studied systematically in these tests. It can be seen from the review above, different unloading rates and different unloading paths were not considered together to research mechanical characteristics of unloading rocks. Thus, experimental studies are needed to provide new insight into the influence of unloading rates and unloading paths on mechanical characteristics of rocks.

In this paper, the specimens are studied in the present study by means of conventional triaxial unloading tests at different unloading paths and different unloading rates. The progressive stress-strain curves and the characteristic deformation behavior were studied. The experimental results have important significance for reasonable excavation and support scheme.

\section{Testing Apparatus}

The study was conducted at the geomechanical test center, on the MTS815 compression machine, under strict test conditions incorporated into the test program. The tester is a rigid machine that MTS Co. Ltd. (USA) produced specifically for versatile rock testing. The machine incorporates electrohydraulic servo control with automatic pressure relief, as well as axis servo control and the measurement system.

\section{Specimen Preparation}

The rock specimens used in this test were drilled from one rock block sampled in a gold mine. The material of the investigated rock specimens is granitic rock. Cylindrical rock specimens were cored by a drill with an inner diameter of $50 \mathrm{~mm}$ along a direction perpendicular to the smooth rock surface; thus, the diameter of the samples ranges between 49 and $49.5 \mathrm{~mm}$. The specimens were cut into pieces $110 \mathrm{~mm}$ in height and showed no apparent cracks or fractures. Then, both ends were finely ground until they measured between 99.5 and $100 \mathrm{~mm}$. The machining accuracy of the specimens was in accordance with the International Society for Rock Mechanics (ISRM) recommended methods [21]. The allowable variations of the end flatness and the deviation from perpendicularity to the longitudinal axis of the specimens were less than $0.02 \mathrm{~mm}$ and $0.001 \mathrm{rad}$, respectively. Rock specimens were granitic rock measuring $\varphi 50 \mathrm{~mm} \times$ $100 \mathrm{~mm}$. The specimens had a longitudinal wave velocity of
TABLE 1: Initial geostress condition of various rock samples.

\begin{tabular}{|c|c|c|c|c|c|}
\hline Paths & Number & $\begin{array}{c}\sigma_{3} \\
(\mathrm{MPa})\end{array}$ & $\begin{array}{c}\sigma_{1} \\
(\mathrm{MPa})\end{array}$ & $\begin{array}{c}v_{\sigma_{3}} \\
\left(\mathrm{MPa} \cdot \mathrm{s}^{-1}\right)\end{array}$ & $\begin{array}{c}v_{\sigma_{1}} \\
\left(\mathrm{MPa} \cdot \mathrm{s}^{-1}\right)\end{array}$ \\
\hline \multirow{12}{*}{ I } & $\mathrm{x} 0-0$ & 10 & 201.52 & 0.05 & 0 \\
\hline & $\mathrm{xl}-0$ & 20 & 265.22 & 0.05 & 0 \\
\hline & $\mathrm{x} 2-0$ & 30 & 301.10 & 0.05 & 0 \\
\hline & $y 0-0$ & 10 & 201.52 & 0.1 & 0 \\
\hline & $y 1-0$ & 20 & 265.22 & 0.1 & 0 \\
\hline & $y 2-0$ & 30 & 301.10 & 0.1 & 0 \\
\hline & $\mathrm{z} 0-0$ & 10 & 201.52 & 0.5 & 0 \\
\hline & $\mathrm{zl}-0$ & 20 & 265.22 & 0.5 & 0 \\
\hline & $\mathrm{z} 2-0$ & 30 & 301.10 & 0.5 & 0 \\
\hline & b0-0 & 10 & 201.52 & 1.0 & 0 \\
\hline & b1-0 & 20 & 265.22 & 1.0 & 0 \\
\hline & b2-0 & 30 & 301.10 & 1.0 & 0 \\
\hline \multirow{12}{*}{ II } & $\mathrm{x} 0-1$ & 10 & 201.52 & 0.05 & -0.05 \\
\hline & $\mathrm{xl}-1$ & 20 & 265.22 & 0.05 & -0.05 \\
\hline & $\mathrm{x} 2-1$ & 30 & 301.10 & 0.05 & -0.05 \\
\hline & y0-1 & 10 & 201.52 & 0.1 & -0.1 \\
\hline & yl-1 & 20 & 265.22 & 0.1 & -0.1 \\
\hline & $y 2-1$ & 30 & 301.10 & 0.1 & -0.1 \\
\hline & $\mathrm{z} 0-1$ & 10 & 201.52 & 0.5 & -0.5 \\
\hline & zl-1 & 20 & 265.22 & 0.5 & -0.5 \\
\hline & $\mathrm{z} 2-1$ & 30 & 301.10 & 0.5 & -0.5 \\
\hline & b0-1 & 10 & 201.52 & 1.0 & -1.0 \\
\hline & b1-1 & 20 & 265.22 & 1.0 & -1.0 \\
\hline & b2-1 & 30 & 301.10 & 1.0 & -1.0 \\
\hline \multirow{12}{*}{ III } & $\mathrm{x} 0-2$ & 10 & 201.52 & 0.05 & 0.05 \\
\hline & $\mathrm{xl}-2$ & 20 & 265.22 & 0.05 & 0.05 \\
\hline & $\mathrm{x} 2-2$ & 30 & 301.10 & 0.05 & 0.05 \\
\hline & $y 0-2$ & 10 & 201.52 & 0.1 & 0.1 \\
\hline & yl-2 & 20 & 265.22 & 0.1 & 0.1 \\
\hline & $y 2-2$ & 30 & 301.10 & 0.1 & 0.1 \\
\hline & $\mathrm{z} 0-2$ & 10 & 201.52 & 0.5 & 0.5 \\
\hline & $\mathrm{zl}-2$ & 20 & 265.22 & 0.5 & 0.5 \\
\hline & $\mathrm{z} 2-2$ & 30 & 301.10 & 0.5 & 0.5 \\
\hline & b0-2 & 10 & 201.52 & 1.0 & 1.0 \\
\hline & b1-2 & 20 & 265.22 & 1.0 & 1.0 \\
\hline & b2-2 & 30 & 301.10 & 1.0 & 1.0 \\
\hline
\end{tabular}

$3200 \sim 3800 \mathrm{~m} / \mathrm{s}$, a density of $2.5 \mathrm{~g} / \mathrm{cm}^{3}$, and a uniaxial compressive strength of $80 \mathrm{MPa}$.

\section{Testing Methodology}

The specimens are put into three schemes for being tested under different initial conditions as listed in Table 1 . The axial pressure which is $80 \%$ of triaxial strength is applied in a strain-controlled way. The initial confining pressure is set to be three levels, 10,20 , and $30 \mathrm{MPa}$, respectively. The unloading rate is set to be four levels, $0.05 \mathrm{MPa} / \mathrm{s}, 0.1 \mathrm{MPa} / \mathrm{s}$, $0.5 \mathrm{MPa} / \mathrm{s}$, and $1 \mathrm{MPa} / \mathrm{s}$. The test steps are as follows. 
(1) Using hydrostatic pressure, the axial stress $\sigma_{1}$ is increased to the initial lateral stress $\sigma_{3}$, maintaining $\sigma_{1}=\sigma_{3}$.

(2) The axial stress $\sigma_{1}$ is increased to $80 \%$ of the peak intensity, maintaining a constant $\sigma_{3}$.

(3) The axial stress and lateral stress are varied at different unloading rates until the specimen is destroyed. In this step, there are three schemes: Scheme I: maintaining a constant for axial pressure while decreasing confining pressure; Scheme II: increasing axial pressure while decreasing confining pressure; Scheme III: decreasing axial pressure and confining pressure. Initial condition of various specimens is shown in Table 1.

\section{Test Results}

5.1. Characteristics of Stress Strain Curves. Figure 1 shows the relationship between the stress and strain of specimens under unloading conditions. Observations from Figure 1 can be summarized as follows.

(1) The axial strain increases slowly, and the lateral strain increases rapidly. The increment of lateral strain is $4 \sim 15$ times than that of axial strain during the process of unloading confining pressures in three paths. It should be noted that the volume strain changed into negative in Figure 1, which indicates that the dilatancy of specimens occur. It shows the lateral tension. The dilatancy of specimens in path II is not obvious; this is because the deviatoric stress increased in path II. It provides more energy to the specimens, which accelerated the damage of rock, accelerated the crack extension, and accelerated the macro failure of specimens. In path III, the dilatancy of specimens is most obvious. Because the unloading time in path III is greater than that in path I and path II.

(2) The increment of axial strain decreases with unloading rates of confining pressures increases. When the unloading rate is $0.05 \mathrm{MPa} / \mathrm{s}, 0.1 \mathrm{MPa} / \mathrm{s}$, and $0.5 \mathrm{MPa} / \mathrm{s}$ in path III, the increment of axial strain changes into negative. In addition, it can be seen that the increment of axial strain decreases with initial confining pressures increases. When the initial confining pressures are $20 \mathrm{MPa}$ and $30 \mathrm{MPa}$, the increment of axial strain reduced approximately $20 \%$ and $40 \%$ compared with $10 \mathrm{MPa}$. This indicates that the unloading rates of confining pressures and initial confining pressures increases, the brittle failure characteristics of specimens is more obvious.

5.2. Deformation Characteristics. To describe the deformation characteristics of specimens in the process of unloading, it presents a description variable-variation of strain increment. The variation of the strain increment is the ratio of strain increment at any time point and strain increment in all process of unloading. They are defined below:

$$
\begin{gathered}
D_{\mathrm{ax}}=\frac{\left(\Delta \varepsilon_{\mathrm{ax}}\right)_{i}}{\sum \Delta \varepsilon_{\mathrm{ax}}}, \\
D_{\text {lat }}=\frac{\left(\Delta \varepsilon_{\mathrm{lat}}\right)_{i}}{\sum \Delta \varepsilon_{\mathrm{lat}}},
\end{gathered}
$$

where $D_{\mathrm{ax}}$ and $D_{\text {lat }}$ are the variation of strain increment of axial and lateral, respectively; $\varepsilon_{\mathrm{ax}}$ and $\varepsilon_{\text {lat }}$ are the axial and lateral, respectively; and $i$ is any time point in the process of unloading.

According to the equation mentioned above, the respective $D_{\mathrm{ax}}$ and $D_{\text {lat }}$ are calculated, and then the evolution of them is analyzed. Figure 2 shows the relationship between the variation of unloading confining pressure $30 \mathrm{MPa}$ increment and the two variables. As shown in Figure 2, the evolution of variables may be summarized as follows.

(1) Firstly, the curve shows the linear steady evolution stage, in which there are linear increases of the variation of strain increment of axial and lateral until the variation of unloading confining pressure is between 0.5 and 0.6 in path I. Additionally, the variation of strain increment of axial and lateral is about $20 \%$ of the variation of total strain increment. It indicates that the damage of specimens grows slowly with the variation of unloading confining pressure increases in this stage, suggesting that the microcracks have initiated and increased steadily, while no interaction has occurred among the cracks. Then, the curve shows the nonlinear evolution stage. About $80 \%$ of the variation of strain increment of axial and lateral occurs in this stage. This indicates that lots of microcracks are produced and opened rapidly, resulting in fast increases of strain. Also, it can be seen from the Figure 2, the unloading rates have a little influence on the variation of strain increment of axial and lateral in whole unloading process.

(2) The variation of strain increment of axial is slightly larger than that of lateral at same time in path II. And the difference between them is affected by unloading rates. When the unloading rate increases from $0.05 \mathrm{MPa} / \mathrm{s}$ to $1 \mathrm{MPa} / \mathrm{s}$, the difference between them increases firstly and then decreases. Additionally, about $60 \% \sim 80 \%$ of the variation of strain increment occurs with the variation of unloading confining pressure change from 0.8 to 1.0 . Also, the variation of strain increment increases with unloading rates increases.

(3) In path III, the variation of the strain increment of axial decreases firstly and then increases with the variation of unloading confining pressure increases. And the rule decreases firstly and then increases with the unloading rates increases. These results indicate that the axial strain is rebound with the unloading of axial in the initial stage. When the variation of unloading confining pressure is larger than 0.4 or so, 

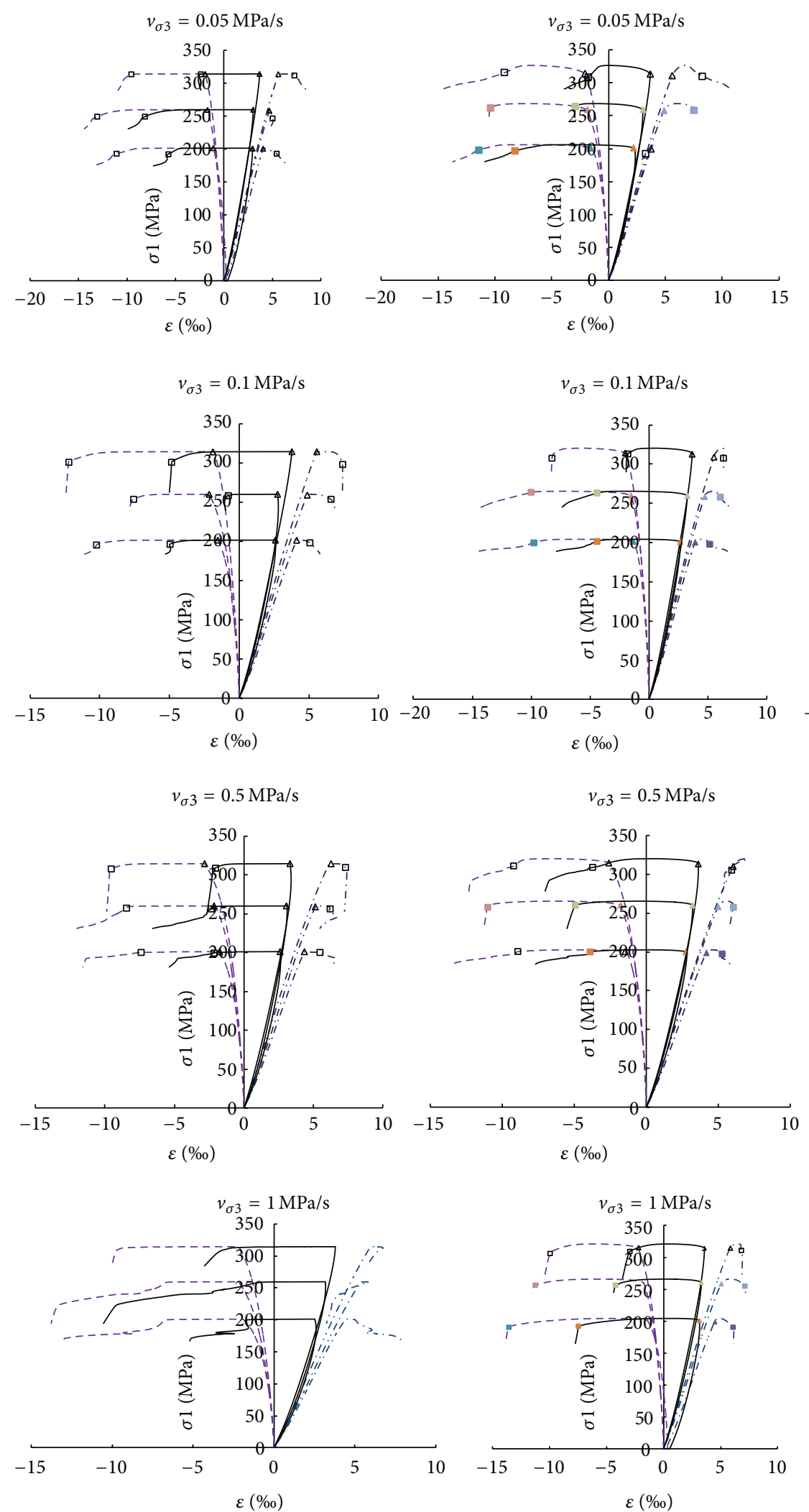

_ Lateral $\quad .-\cdot$ Axial strain

(I)

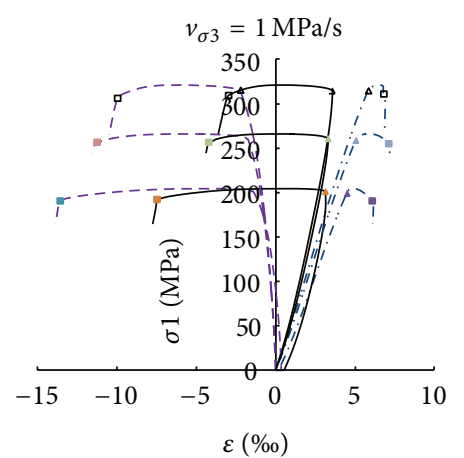

_ Lateral ... Axial strain - - - Volumetric strain

(II)
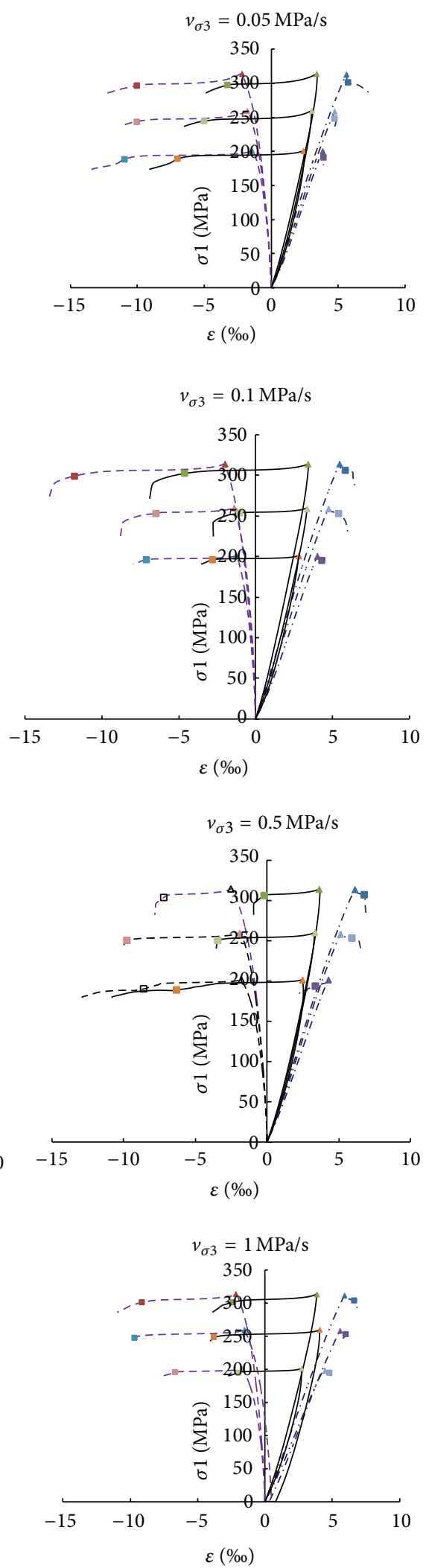

_ Lateral ...- Axial strain - - - Volumetric strain

(III)

FIGURE 1: Complete stress-strain curves of rock under different paths and unloading rates of confining pressures. 

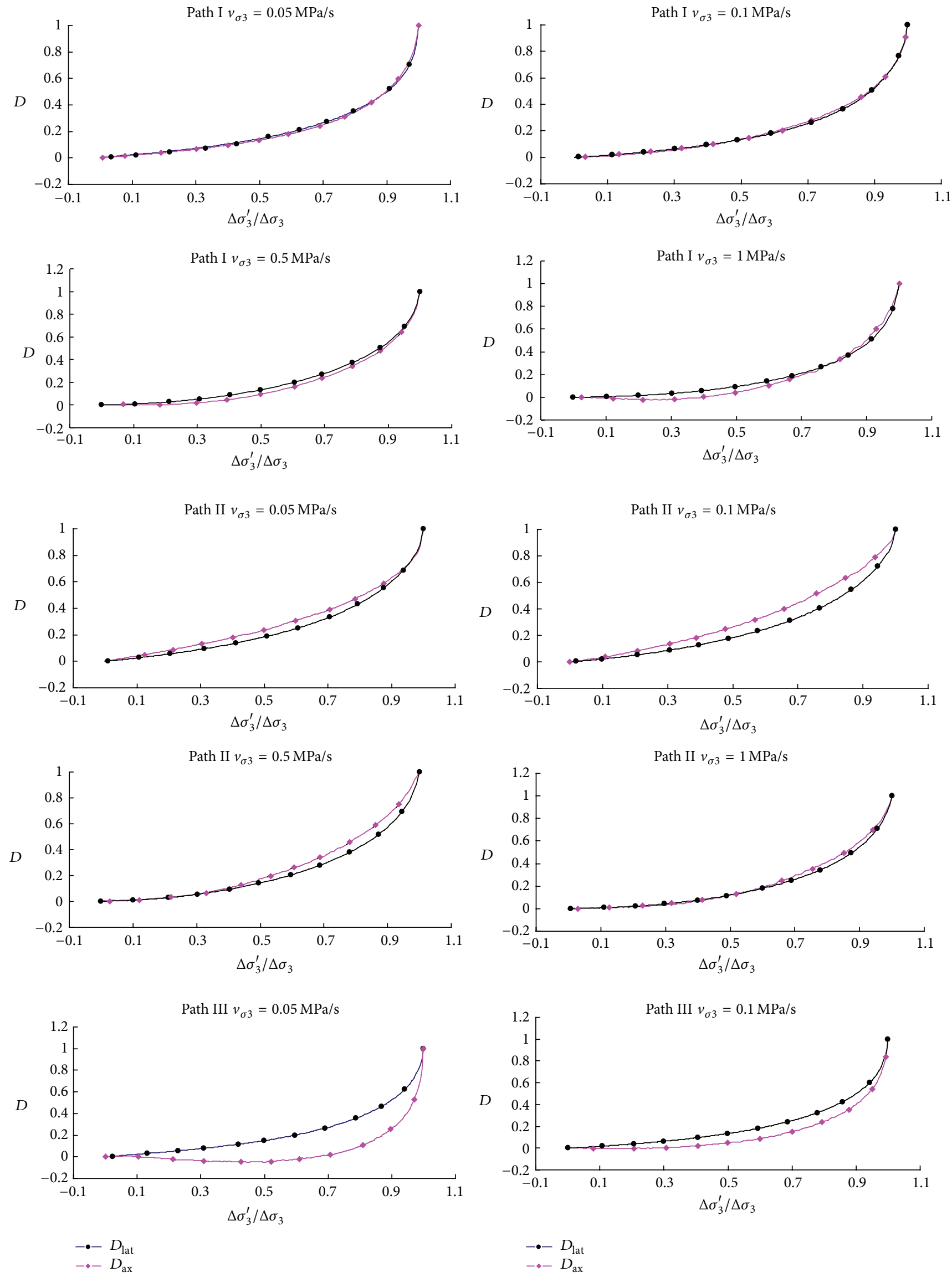

Figure 2: Continued. 

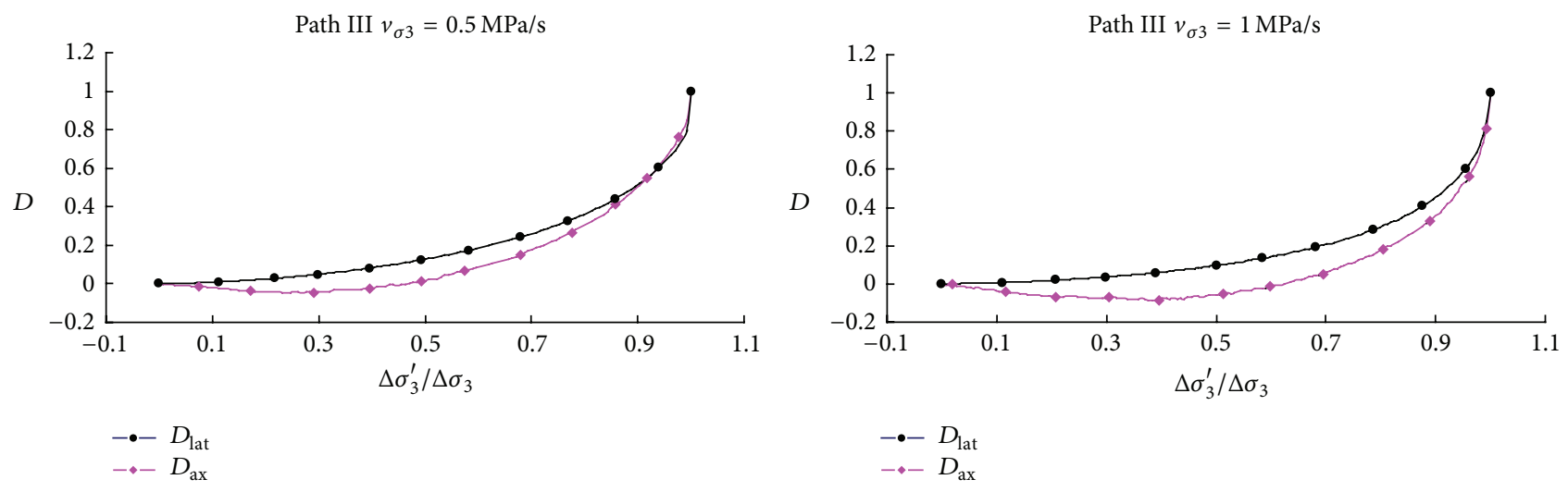

FIGURE 2: The evolution of variation of axial strain increment with unloading confining pressures.

the variation of strain increment of axial gradually increases. It indicates that interaction has occurred among cracks, resulting in rapid increases of strain, and the dilatancy of specimens has occurred obviously in path III.

5.3. Analysis of Dilation Characteristics. In the theory of rock mechanics, the dilatancy angle $\psi$ is usually used to describe the dilation characteristics. Vermeer and de Borst [22] defined the dilatancy angle as follows:

$$
\psi=\arcsin \left(\frac{\varepsilon_{v}^{\prime}}{-2 \varepsilon_{1}^{\prime}+\varepsilon_{v}^{\prime}}\right),
$$

where $\varepsilon_{1}^{\prime}$ and $\varepsilon_{v}^{\prime}$ are the strain increment of axial and volumetric, respectively.

Figure 3 shows the evolution of dilatancy angle $\psi$ with the variation of strain increment lateral in process of unloading confining pressures.

(1) From Figure 3, it can be seen that the initial confining pressure has an important influence on the dilatancy angle $\psi$, which decreases with the initial confining pressure increases. This indicates that the initial confining pressure hinders the dilatancy angle to extend.

(2) The evolution of dilatancy angle first increases slowly to about 1.5 times of the initial dilatancy angle, then maintain approximate the same dilatancy angle until the rock failures with $0.05 \mathrm{MPa} / \mathrm{s}$ of unloading rate. As the unloading rate adds up to $0.1 \mathrm{MPa} / \mathrm{s}$, the dilatancy angle quickly enhances and reaches a limit value, then decreases a bit, and ultimately reaches a fixed value. When the unloading rate ranges from $0.5 \mathrm{MPa} / \mathrm{s}$ to $1 \mathrm{MPa} / \mathrm{s}$, the dilatancy angle reaches a limit value more rapidly that is $2 \sim 5$ times of the initial dilatancy angle, then reduced to a fixed level until the rock failures.

(3) It is particularly worth noting that the rate of dilatancy angle from initial value to limit value increases with the unloading rates increases, as shown in Figure 3. It indicates that when the unloading rate is rapid, the strain energy quickly releases, resulting in many microcracks produced and expanded. It leads to an increase of the lateral strains occur and propagate, but the axial strains have less time to expanded, generating the process of dilatancy angle increases fast. Then, with the unloading, the strain energy is consumed by extending of microcracks, the dilatancy angle decreases slowly to a stable state until the rock failures.

(4) Compared with the rate of dilatancy angle from initial value to limit value in path I and path II, the rate of dilatancy angle from initial value to limit value in path I is greater than that in path II with the same unloading rates. The result indicates that loading of axial in path II provides more energy to rock, some microcracks expanded rapidly, resulting in the dilatancy angle increasing rapidly.

\section{Conclusions}

(1) The axial strain increases slowly, and the lateral strain increases rapidly in the process of unloading; the dilatancy of specimens occurs. In path III, the dilatancy of specimens is the most obvious. The unloading rates of confining pressures and initial confining pressures increase; the brittle failure characteristics of specimens are more obvious.

(2) A description variable-variation of strain increment is presented in this paper. According to the relationships between variation of strain increment and variation of the confining pressure, there are linear increases of the variation of strain increment of axial and lateral until the variation of unloading confining pressure is between 0.5 and 0.6 in path I. The variation of strain increment of axial is slightly larger than that of lateral at same time in path II. The difference between them is affected by unloading rates. In path III, the variation of strain increment of axial decreases firstly and then increases with the variation of unloading confining pressure increases. The rule decreases firstly and then increases with the unloading rates increases. 

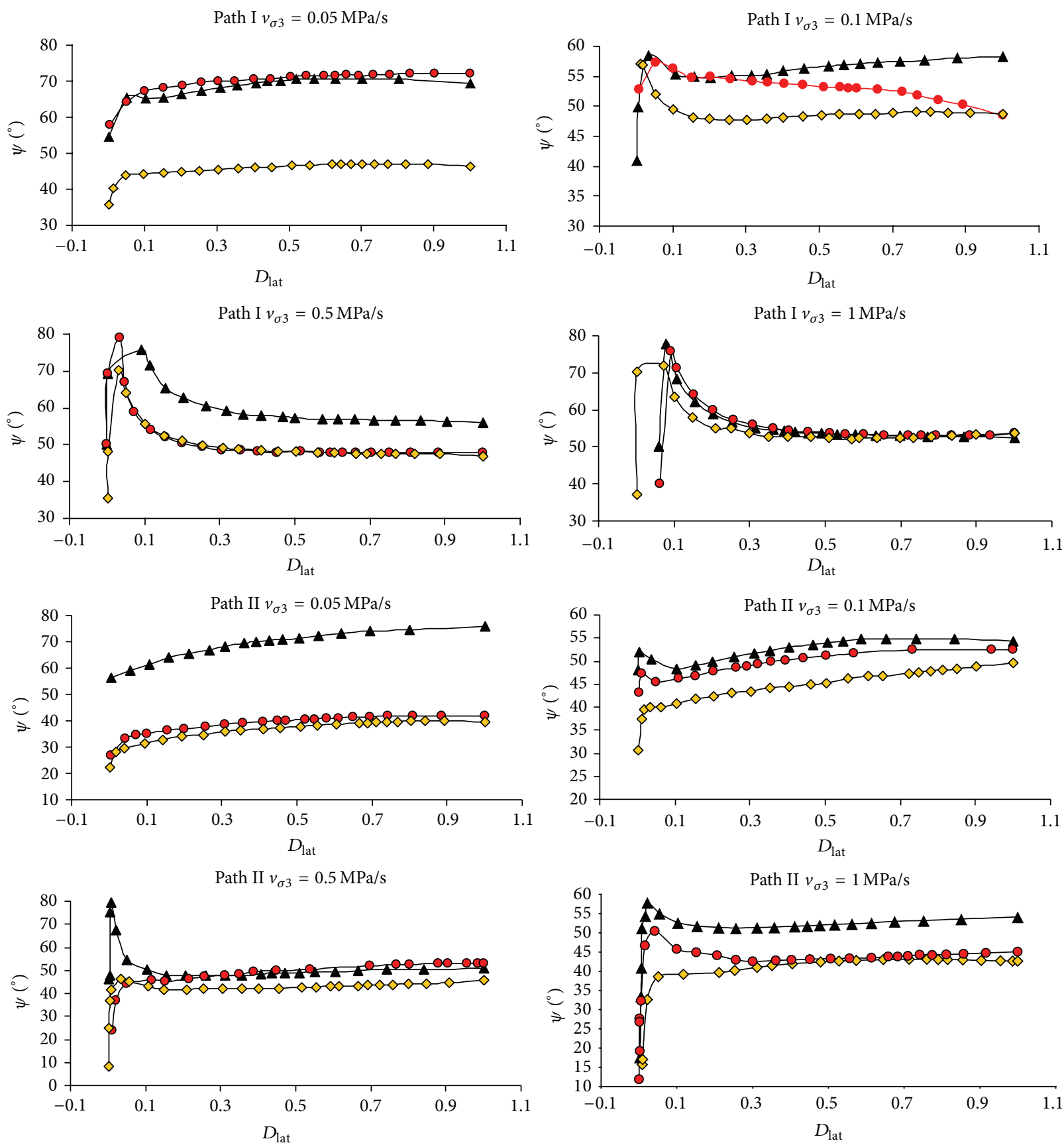

-₫- The initial confining pressure is $10 \mathrm{MPa}$
-૦- The initial confining pressure is $20 \mathrm{MPa}$
- - The initial confining pressure is $30 \mathrm{MPa}$

-₫- The initial confining pressure is $10 \mathrm{MPa}$
-๑- The initial confining pressure is $20 \mathrm{MPa}$
- - The initial confining pressure is $30 \mathrm{MPa}$

FIGURE 3: The evolution of dilatancy angle with variation of lateral strain increment.

(3) According to the analysis of the evolution of dilatancy angle with the variation of strain increment lateral, the initial confining pressure has an important influence on the dilatancy angle $\psi$, which decreases with the initial confining pressure increases. The rate of dilatancy angle from initial value to limit value increases with the unloading rates increases. The rate of the dilatancy angle from the initial value to the limit value in path I is greater than that in path II under the same unloading rates.

\section{Conflict of Interests}

The authors declare that there is no conflict of interests regarding the publication of this paper. 


\section{References}

[1] W. Gang, S. Jun, and W. Zhong-ru, "Damage mechanical analysis of unloading failure of intact rock under complex stress state," Journal of Hehai University, vol. 25, no. 3, pp. 44-49, 1997.

[2] L.-J. Dong and X.-B. Li, "Three-dimensional analytical solution of acoustic emission source location for cuboid monitoring network without pre-measured wave velocity," Transactions of Nonferrous Metals Society of China, vol. 25, no. 1, pp. 293-302, 2015.

[3] L.-J. Dong and X.-B. Li, "Three-dimensional analytical solution of acoustic emission or microseismic source location under cube monitoring network," Transactions of Nonferrous Metals Society of China, vol. 22, no. 12, pp. 3087-3094, 2012.

[4] L.-J. Dong and X.-B. Li, "A microseismic/acoustic emission source location method using arrival times of PS waves for unknown velocity system," International Journal of Distributed Sensor Networks, vol. 2013, Article ID 307489, 8 pages, 2013.

[5] L.-J. Dong, X.-B. Li, and G. Xie, "An analytical solution for acoustic emission source location for known $\mathrm{P}$ wave velocity system," Mathematical Problems in Engineering, vol. 2014, Article ID 290686, 6 pages, 2014.

[6] X. Li, W. Cao, Z. Zhou, and Y. Zou, "Influence of stress path on excavation unloading response," Tunnelling and Underground Space Technology, vol. 42, pp. 237-246, 2014.

[7] Y. Ming-qing and H. An-zeng, "Tri-axial confining depressure test of rock sample," Chinese Journal of Rock Mechanics and Engineering, vol. 17, no. 1, pp. 24-29, 1998.

[8] Q.-R. Huang and D. Huang, "Experimental research on affection laws unloading rates on mechanical properties of Jinping marble under high geostress," Chinese Journal of Rock Mechanics and Engineering, vol. 29, no. 1, pp. 21-33, 2010.

[9] L.-J. Dong, X.-B. Li, and K. Peng, "Prediction of rockburst classification using Random Forest," Transactions of Nonferrous Metals Society of China (English Edition), vol. 23, no. 2, pp. 472477, 2013.

[10] M. C. Torres-Suarez, A. Alarcon-Guzman, and R. Berdugo-De Moya, "Effects of loading-unloading and wetting-drying cycles on geomechanical behaviors of mudrocks in the Colombian Andes," Journal of Rock Mechanics and Geotechnical Engineering, vol. 6, no. 3, pp. 257-268, 2014.

[11] H. Q. Yang, Y. Y. Zeng, Y. F. Lan, and X. P. Zhou, "Analysis of the excavation damaged zone around a tunnel accounting for geostress and unloading," International Journal of Rock Mechanics and Mining Sciences, vol. 69, pp. 59-66, 2014.

[12] L. F. Fan and L. N. Y. Wong, "Stress wave transmission across a filled joint with different loading/unloading behavior," International Journal of Rock Mechanics and Mining Sciences, vol. 60, pp. 227-234, 2013.

[13] R. Q. Huang and D. Huang, "Evolution of rock cracks under unloading condition," Rock Mechanics and Rock Engineering, vol. 47, no. 2, pp. 453-466, 2014.

[14] R. Q. Huang, X. N. Wang, and L. S. Chan, "Triaxial unloading test of rocks and its implication for rock burst," Bulletin of Engineering Geology and the Environment, vol. 60, no. 1, pp. 3741, 2001.

[15] J. Li, X. Chen, L. Dang, Y. Dong, Z. Cheng, and J. Guo, “Triaxial unloading test of sandstone after high temperature," Chinese Journal of Rock Mechanics and Engineering, vol. 30, no. 8, pp. 1587-1595, 2011.

[16] M. Cai, "Influence of stress path on tunnel excavation response-numerical tool selection and modeling strategy,"
Tunnelling and Underground Space Technology, vol. 23, no. 6, pp. 618-628, 2008.

[17] Y.-T. Guo, C.-H. Yang, and H.-J. Mao, "Mechanical properties of Jintan mine rock salt under complex stress paths," International Journal of Rock Mechanics and Mining Sciences, vol. 56, pp. 5461, 2012.

[18] Y.-T. Guo, C.-H. Yang, and J.-J. Fu, "Experimental research on mechanical characteristics of salt rock under triaxial unloading test," Rock and Soil Mechanics, vol. 33, no. 3, pp. 725-738, 2012.

[19] S.-L. Qiu, X.-T. Feng, J.-Q. Xiao, and C.-Q. Zhang, "An experimental study on the pre-peak unloading damage evolution of marble," Rock Mechanics and Rock Engineering, vol. 47, no. 2, pp. 401-419, 2014.

[20] S.-L. Qiu, X.-T. Feng, and C.-Q. Zhang, "Experimental research on mechanical properties of deep-buried marble under different unloading rates of confining pressures," Chinese Journal of Rock Mechanics and Engineering, vol. 29, no. 9, pp. 1807-1817, 2010.

[21] R. Ulusay and J. A. Hudson, The Complete ISRM Suggested Methods for Rock Characterization, Testing and Monitoring: 1974-2006, International Society for Rock Mechanics, 2007.

[22] P. A. Vermeer and R. de Borst, "Non-associated plasticity for soils, concrete and rock," Heron, vol. 29, 3, pp. 1-64, 1984. 

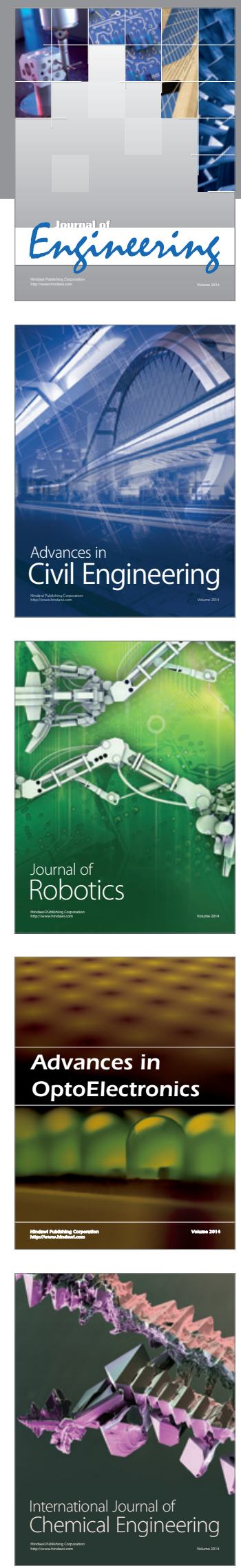

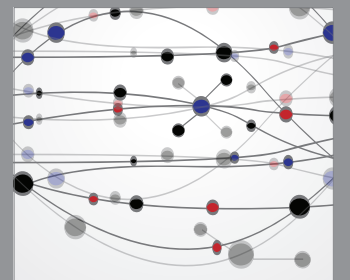

The Scientific World Journal
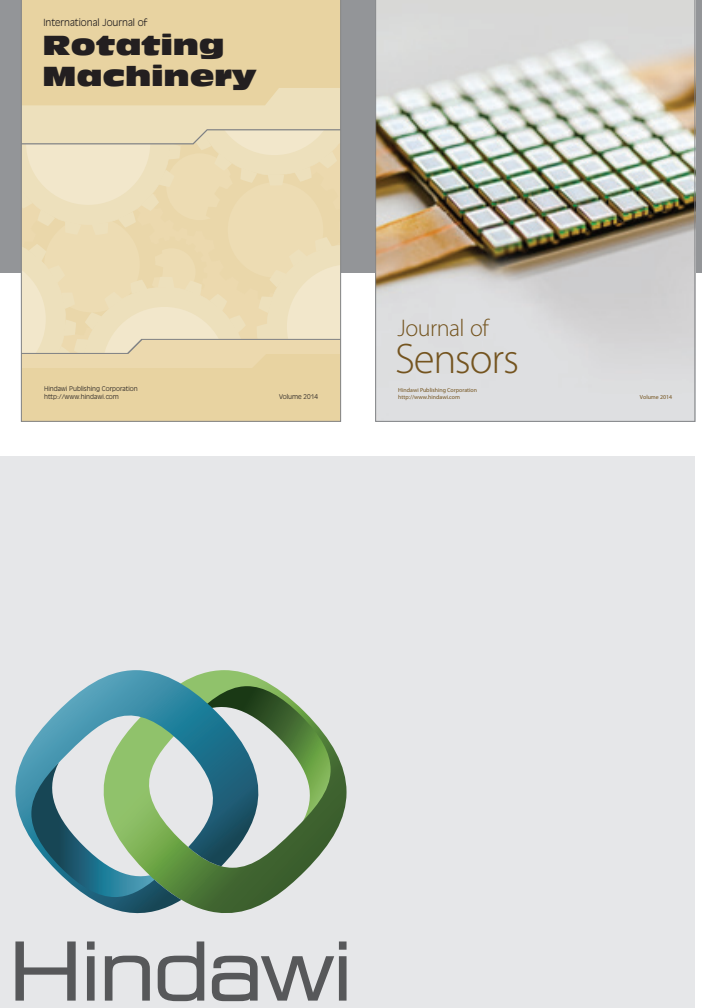

Submit your manuscripts at http://www.hindawi.com
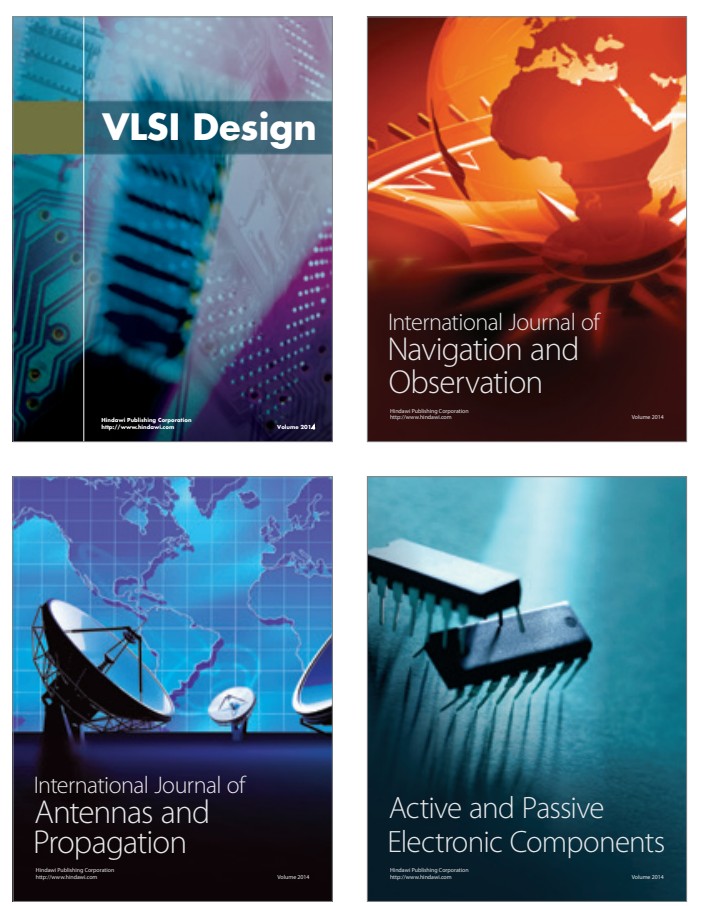
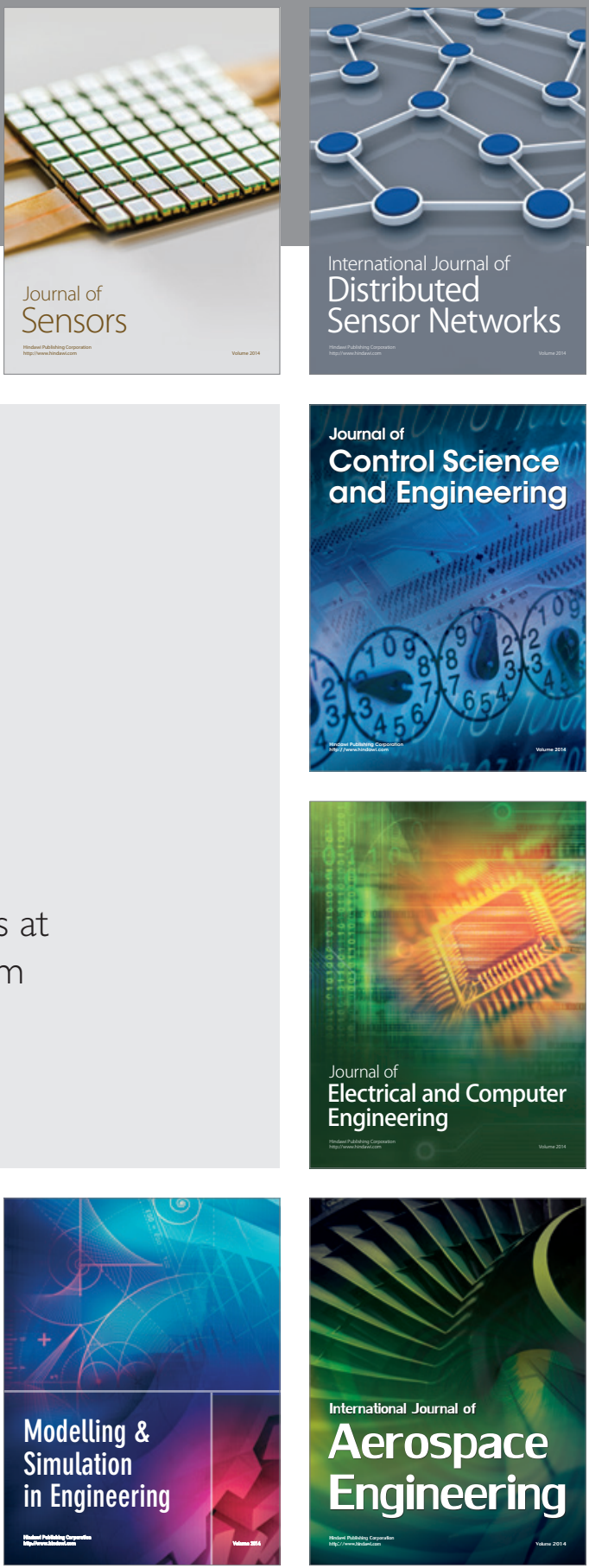

Journal of

Control Science

and Engineering
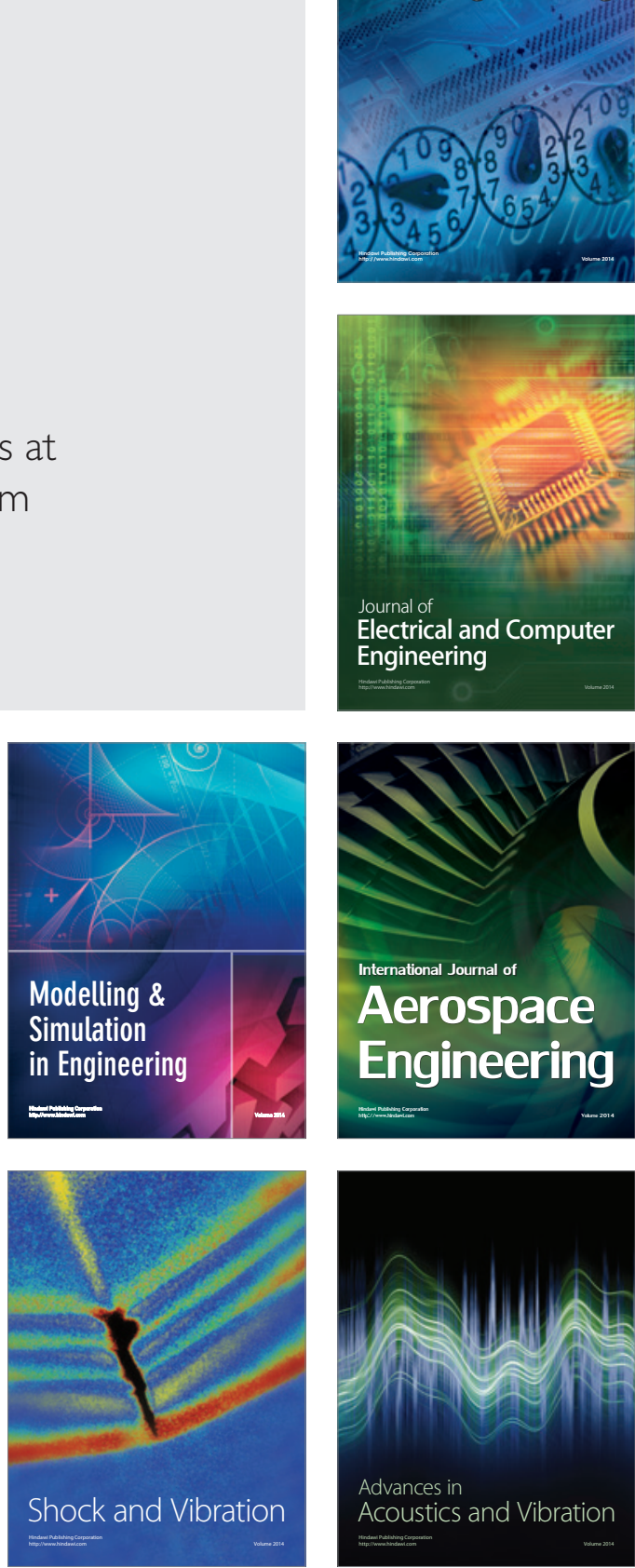